\title{
THE APRIL MEETING IN CHICAGO
}

The three hundred thirty-first meeting of the American Mathematical Society was held at the University of Chicago on Friday and Saturday, April 10-11, 1936. There were about one hundred thirty-five persons in attendance among whom were the following ninety-two members of the Society:

A. A. Albert, G. E. Albert, M. R. Anderson, S. F. Barber, R. H. Bardell, I. A. Barnett, Walter Bartky, E. F. Beckenbach, M. M. Beenken, Theodore Bennett, H. R. Beveridge, G. A. Bliss, Henry Blumberg, H. R. Brahana, R. S. Burington, L. E. Bush, W. H. Bussey, Max Coral, J. J. Corliss, D. R. Curtiss, W. M. Davis, W. W. Denton, L. E. Dickson, D. M. Dribin, E. B. Escott, H. P. Evans, H. S. Everett, H. H. Goldstine, L. W. Griffiths, V. G. Grove, V. C. Harris, W. L. Hart, O. C. Hazlett, D. L. Holl, Ralph Hull, M. H. Ingraham, Dunham Jackson, R. L. Jeffery, E. D. Jenkins, Fritz John, P. W. Ketchum, W. S. Kimball, J. M. Kinney, S. C. Kleene, W. C. Krathwohl, A. C. Ladner, Cornelius Lanczos, C. G. Latimer, C. A. Lester, M. I. Logsdon, A. C. Lunn, C. C. MacDuffee, W. D. MacMillan, Morris Marden, A. E. May, J. R. Mayor, L. E. Mehlenbacher, U. G. Mitchell, D. C. Morrow, E. J. Moulton, A. L. Nelson, E. A. Nordhaus, Rufus Oldenburger, G. A. Parkinson, E. D. Pepper, Tibor Radó, G. Y. Rainich, R. B. Rasmusen, W. T. Reid, P. G. Robinson, A. E. Ross, W. E. Roth, N. E. Rutt, R. G. Sanger, Henry Scheffé, Henry Schultz, Nathan Schwid, H. A. Simmons, Burke Smith, E. S. Sokolnikoff, I. S. Sokolnikoff, G. G. Speeker, R. C. Stephens, E. B. Stouffer, Gabriel Szegö, H. P. Thielman, R. W. Wagner, K. W. Wegner, O. L. Wheeler, E. P. Wiggin, F. B. Wiley, F. E. Wood.

The meeting opened on Friday morning with two sectional sessions, one on Algebra and one on Analysis and Geometry. The Symposium Lecture was delivered Friday afternoon by Professor Tibor Radó of Ohio State University on Some geometrical applications of conformal mapping. Saturday morning was devoted to a general session.

The dinner which was held at Judson Court on Friday was attended by about one hundred mathematicians and their guests. Dean E. B. Stouffer of the University of Kansas acting as toastmaster invited those present to attend the meeting of the Society at Lawrence, Kansas, next November. He then called upon Professor R. L. Jeffery of Acadia University who is teaching this year at the University of Wisconsin, Dr. E. F. Beckenbach of Rice Institute, and Professor D. R. Curtiss of Northwestern University. 
Friday morning Professor C. C. MacDuffee of the University of Wisconsin and Professor C. G. Latimer of the University of Kentucky alternated as chairmen of the Algebra Section, and Professor U. G. Mitchell of the University of Kansas presided at the Section on Analysis and Geometry. The Symposium Lecture and the General Session on Saturday were presided over by Dean E. B. Stouffer of the University of Kansas and Dean W. H. Bussey of the University of Minnesota, respectively.

The titles of papers read at the meeting follow. Those whose abstract numbers are followed by $t$ were read by title. Papers numbered 1 to 8 were given in the Algebra Section, those numbered 9 to 18 in the Analysis and Geometry Section, and those numbered 19 to 46 in the General Session. Paper number 5 was read by Professor G. Y. Rainich.

1. Rational equivalence of a form to a sum of pth powers (preliminary report), by Dr. Rufus Oldenburger. (Abstract No. 42-7-285.)

2. On the rational equivalence of pairs of Hermitian matrices, by Mr. A. E. May. (Abstract No. 42-5-159.)

3. On ideals in a quaternion ring and the representation of integers by Hermitian forms, by Professor C. G. Latimer. (Abstract No. 42-5-151.)

4. On a fundamental theorem in matric theory, by Professor C. C. MacDuffee. (Abstract No. 42-5-170.)

5. Note on group postulates, by Mr. Herbert Boggs and Professor G. Y. Rainich. (Abstract No. 42-5-168.)

6. On quadratic rings and the arithmetics of quaternion algebras, by Dr. Ralph Hull. (Abstract No. 42-5-155.)

7. Canonical form as a many-valued function in matrix space (preliminary report), by Mr. R. W. Wagner. (Abstract No. 42-5-167.)

8. A simple recursion method for solving a set of linear equations, by Professor Cornelius Lanczos. (Abstract No. 42-5-173.)

9. Arithmetic genus of an algebraic variety, by Dr. S. F. Barber. (Abstract No. 42-3-131.)

10. Differential geometry of a surface at a planar point, by Professor V. G. Grove. (Abstract No. 42-3-117.)

11. A generalization of the elementary transcendental functions by means of a theorem of Volterra, by Professor H. P. Thielman. (Abstract No. 42-3-128.) 
12. Identities between certain sums and integrals, by Professor Fritz John. (Abstract No. 42-5-171.)

13. New basic necessary conditions and methods in the calculus of variations, by Professor W. S. Kimball. (Abstract No.42-5-153.)

14. The interrelations of the fundamental solutions of the hypergeometric equation, by Mr. L. E. Mehlenbacher. (Abstract No. 42-5-169.)

15. A note on critical points, by Professor Morris Marden. (Abstract No. 42-5-234.)

16. An analog to the Fekete theorem for the critical points of Green's function, by Professor Morris Marden. (Abstract No. 42-3-124-t.)

17. On the relation of Appell polynomials to orthogonal polynomials, by Dr. M. S. Webster. (Abstract No. 42-3-127-t.)

18. On the topology of a two-parameter, non-metric, and nonseparable space, by Dr. E. G. Harrell. (Abstract No. 42-5-165-t.)

19. On the expansion of a function holomorphic in distinct regions, by Dr. P. W. Ketchum. (Abstract No. 42-3-118.)

20. A lemma on the topological index, by Professor Tibor Radó. (Abstract No. 42-3-125.)

21. Definitely self-adjoint boundary-value problems, by Professor G. A. Bliss. (Abstract No. 42-5-156.)

22. A system of ordinary linear differential equations with twopoint boundary conditions, by Dr. W. T. Reid. (Abstract No. 42-5-157.)

23. The diagonal summation of double Fourier series, by Professor Dunham Jackson. (Abstract No. 42-5-158.)

24. Functions of bounded variation in two or more variables, by Professor R. L. Jeffery. (Abstract No. 42-5-160.)

25. Proof of the ideal Waring theorem for exponents exceeding six, by Professor L. E. Dickson. (Abstract No. 42-5-231.)

26. Remark on the deviation from analyticity of a non-analytic function, by Professor G. Y. Rainich. (Abstract No. 42-5-166.)

27. Sub-F $(x ; \alpha, \beta)$ functions, by Dr. E. F. Beckenbach. (Abstract No. 42-5-163.)

28. Remarks concerning mathematical controversies (preliminary report), by Professor Henry Blumberg. (Abstract No. 42-5-152.)

29. On transformations in the plane. I and II, by Professor Tibor Radó. (Abstract No. 42-3-119-t.) 
30. Proof that every positive integer is a sum of four squares, by Professor R. D. Carmichael. (Abstract No. 42-3-120-t.)

31. On numbers of the form $a^{2}+\alpha b^{2}$, by Professor R. D. Carmichael. (Abstract No. 42-3-121-t.)

32. On non-homogeneous linear differential equations of infinite order with constant coefficients, by Professor R. D. Carmichael. (Abstract No. 42-3-122-t.)

33. On a classification of integral functions by means of certain invariant point properties, by Professor R. D. Carmichael, Dr. W. T. Martin (National Research Fellow), and Dr. M. T. Bird. (Abstract No. 42-3-123-t.)

34. A generalized element of decomposition for doubly periodic functions, by Dr. G. D. Nichols. (Abstract No. 42-3-132-t.)

35. A remark on the area of surfaces, by Professor Tibor Radó. (Abstract No. 42-3-126-t.)

36. Ranks of 4-way matrices, by Dr. Rufus Oldenburger. (Abstract No. 42-3-129-t.)

37. Arithmetic invariants of binary cubic and binary trilinear forms, by Dr. Rufus Oldenburger. (Abstract No. 42-3-130-t.)

38. Integration of certain simple (step) functions, by Dr. H. P. Doole. (Abstract No. 42-5-154-t.)

39. Asymptotic Waring theorems, by Professor L. E. Dickson. (Abstract No. 42-5-232-t.)

40. Generalization of the associative law, by Dr. Max Zorn. (Abstract No. 42-5-161-t.)

41. On the second fundamental theorem in the theory of alternative algebras, by Dr. Max Zorn. (Abstract No. 42-5-162-t.)

42. A certain mean value problem in statistics, by Professor A. T. Craig. (Abstract No. 42-5-164-t.)

43. The integers represented by sets of binary biquadratic forms (preliminary report), by Dr. O. K. Sagen. (Abstract No. 42-5172-t.)

44. Concerning linear difference equations containing a parameter, by Professor W. J. Trjitzinsky. (Abstract No. 42-5-233-t.)

45. Stresses in moderately thick rectangular plates, by $\mathrm{Mr}$. Archie Higdon and Professor D. L. Holl. (Abstract No. 42-5235-t.)

Mark H. Ingraham, Associate Secretary 